\title{
DESIGN OF WORKPLACE FOR THE ASSEMBLY OF MONOBLOCK
}

\section{PUMP}

\author{
R. Arun Prakash ${ }^{1}$, B.S.Arun ${ }^{2}$, Nithin Narayanan ${ }^{3}$, V.Yeshwanth ${ }^{4}$ \\ ${ }^{1}$ Assistant Professor, ${ }^{2,3,4}$ B.E. Student, Department of Production Engineering, PSG College of Technology, Tamil Nadu, \\ India,bsarun19cbe@gmail.com
}

\begin{abstract}
Productivity is an important aspect of every industrial firm as well as for the economic growth of the country. High productivity means completing a quantum of work with minimum possible time and fewer amounts of resources. Work-study is required for designing the work system, which identifies the effective means of completing the work. Also, it is known that the workers suffer from fatigue and injury during long hours of monotonous work when proper workplace/working environment is absent. This may indirectly contribute to decreased productivity in an industry. Human factor issues arise in simple systems and in consumer products as well. Hence the ergonomic principles are to be considered while designing both consumer and industrial products. One of the most prevalent types of work-related injuries is musculoskeletal disorder. Work-related musculoskeletal disorders (WRMDs) results in continuous pain, functional capability loss and disability to work, but the prevailing disorder diagnosis is difficult because they are mainly based on complaints of pain and other symptoms. Hence a proper workplace is to be designed to overcome the above issues or to reduce them considerably. This research aims at improving the existing and proposed ways of doing work with Ergonomics and Anthropometric considerations, thereby improving the productivity rate.
\end{abstract}

Keywords: Productivity, Work study, Ergonomics, Anthropometry, and Monoblock pump.

\section{INTRODUCTION}

Productivity is defined as the relation between the output produced to the amount of input resources used. Productivity is one of the best methods to measure the output of the process. The progress of the improvements in the process is monitored by means of productivity by day to day basis. Productivity will be achieved by following continuous efforts by applying new technique and method of operation. The various reasons affecting the productivity are classified as controllable and non- controllable causes. The controllable causes are given below.

1. Plant and equipment technology level.

2. Materials.

3. Energy

4. Human- resources.

5. Work methods

6. Management.

The non- controllable causes are as follows.

1. Government and infrastructure

2. Natural resources availability.

3. Structural factors.

In our research we consider the Human factors and Work methods. In order to improve productivity, the employer has to train their staff and employees about their specific job, safety, their duties and responsibilities etc. An employer has to give details of each employees employment, place of employment, hazards which will cause or likely to cause serious physical harm or death to prevent accidents during employment.

\section{LITERATURE SURVEY}

Prior to 1980, the industrial application of ergonomics in the United States largely focused on defining physical capabilities of workers and physiological responses to various working conditions. Companies supporting these early ergonomic efforts, mainly through applied industrial research activities included E.I. DuPont de Nemours \& Company and Eastman Kodak Company (Eastman Kodak Company, 1983).

In 1987, OSHA (Occupational Safety and Health Administration in the United States) issued its first ergonomics directive that established regional ergonomics coordinators to provide technical assistance to OSHA area offices, mandated training for compliance staff, and directed compliance safety and health officers to consider ergonomic violations under what is known as the "General Duty Clause"'. The General Duty Clause requires an employer to "furnish to each of his employees employment and a place of employment which are free from recognized hazards that are causing or are likely to cause death or serious physical harm to his employees". Without a specific rule or regulation related to ergonomics, OSHA's compliance personnel used (and continue to use) this General Duty Clause to develop ergonomics related 
citations-often leading to the development of settlement agreements that involved the development of an ergonomics program. In addition to the efforts in the area of compliance, the late 1980s and early 1990s saw OSHA involved in the development of ergonomics assistance materials to help industry deal with the growing problem of work related musculoskeletal disorders.

OSHA (1990) published the Ergonomics Program Management Guidelines for Meatpacking Plants, which defined basic elements of formal ergonomics programs, and served as a template for the meatpacking industry, as well as general industry. Since then, several case studies of ergonomics programs in other industries located in the United States and other countries have been published. Industries identified in these reports included the beverage, cosmetic, telecommunications, electronics, financial planning, automotive, light manufacturing (abrasive products and shoes), health care, utilities and food industries, as well as office environments (Gauf, 1995; US Government Accounting Office, 1997; Perry, 1997; Hignett, 2001; Munck-Ulfsfa“ et al., 2003; Butler, 2003; Smyth, 2003; Joseph, 2003; Moreau, 2003). These case studies generally demonstrated effectiveness with pre and post implementation data, such as reduced injury rates, cost of compensation and loss in working time.

Despite the numerous reports of ergonomic work study programs in a variety of industries, there are no reports of implementing an ergonomic work study program in the assembly of monoblock pumps. The assembly environments pose challenges to implement the ergonomic work study principles.

\section{WORK STUDY}

Work study is used to study the production efficiency of the unit by reducing waste and un- wanted operations. It is a best technique to improve value addition in machine operation by studying all factors affecting the product. The work study is the accurate and system oriented technique to formulate time standards. This will contribute to the company's profit and savings will start continuously with immediate effect for the product throughout life cycle of the product. Method study is achieved through motion study and work measurement is achieved through time study.

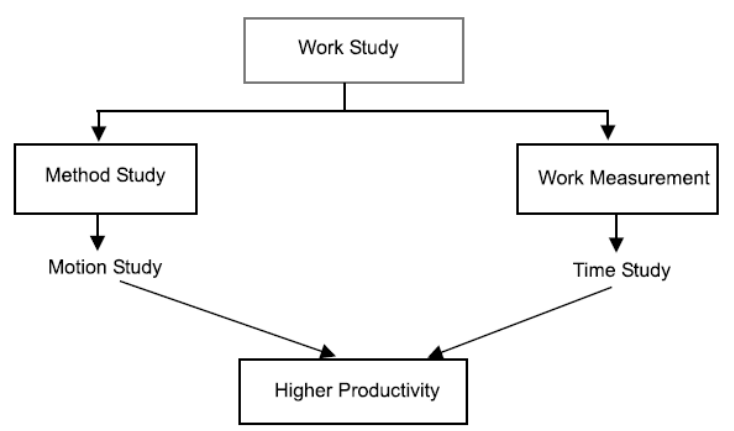

Fig-1: Work study

\subsection{Method Study}

In method study, the industrial engineer is to study each operation with systematic analysis. The major important purpose of method study is to identify and eliminate unwanted operations and to achieve best way of performing the operations. The method study is also termed as methods engineering or work designing. The methods engineering is used to collect all analysis technique with focus on improving performance of men and machinery. Method study is the systematic recording and critical examination of existing \& proposed ways of doing work by designing easier with most efficient methods of operation with reduced cost. Basically, the method study is performed by breaking down an operation into simple parts.

\subsection{Motion Study}

Analysis of the motion of an operator or work will be studied in motion study. The motion study is a part of method study. There are many number of principles used to study economy of movements developed by experience. This will form basis for developing improved methods at work place, proper use of human resources, work place arrangements, tool designing and equipment. Work place height, seat etc., should be designed to allow alternate standing and seating.

\subsection{Time Study}

Time study is important for studying production, planning and control of operations. Time study is used to measure data, production capacity, to quote cost, schedule of delivery, cost of production, man power utilization and efficiency. The proper time study allows the management is to introduce incentive schemes for the best performers and standardizing cost to control budget.

\subsection{Techniques of Time Study}

The work measurement is classified as repeating work and non- repeating work. Each work will be studied. Various techniques of work measurements are time study, PMTS, work sampling and synthesis, etc. 


\subsubsection{Repeating Work}

In this main operation of the work, group of operations repeat continuously during time spent at the job. The repetitive work cycles are of very short duration.

\subsubsection{Non- Repeating Work}

This type consists of some type of maintenance and construction work, where the work is not repeated identically.

Table-1: Work measurement techniques

\begin{tabular}{|c|c|c|}
\hline Techniques & Applications & Unit of measurement \\
\hline 1. Time study & $\begin{array}{l}\text { Short cycle repetitive jobs. } \\
\text { Widely used for direct work. }\end{array}$ & Centiminute (0.01 min) \\
\hline 2. Synthetic Data & Short cycle repetitive jobs. & Centi minutes \\
\hline 3. Working sampling & $\begin{array}{l}\text { Long cycle jobs/heterogeneous } \\
\text { operations. }\end{array}$ & Minutes \\
\hline 4. MTM & $\begin{array}{l}\text { Manual operations confined to } \\
\text { one work centre. }\end{array}$ & TMU $(1 \mathrm{TMU}=0.006 \mathrm{~min})$ \\
\hline 5. Analytical estimation & Short cycle non-repetitive job. & Minutes \\
\hline
\end{tabular}

\subsection{Computation of Standard Time}

Standard time is the time allowed to an operator to perform the task specified with specified conditions and defined level of performance. To get standard time, the various allowances are added to normal time as applicable to perform a job by an operator. Time required completing a unit of work with existing working condition, using specified method and machine; proper working of an operator and at standard pace is defined as standard time. Constituents of standard time are observed time, performance rating, allowance for relaxation, Interference, contingency, policy etc.

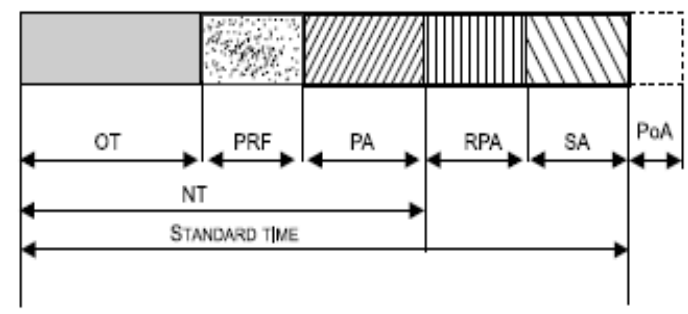

Fig-2: Standard time

\section{MOTIVATION AND APPROACH}

As seen from the above literature review, one of the important considerations to be given in today's industries is the physical comfort of the worker in his/her working environment which indirectly leads to growth of the industry and in such a scenario, ergonomics plays a vital role. One important cause for undertaking this project is that there is no aid for conducting ergonomic analysis for the people relating to Indian origin as some software packages like CATIA, PRO-E, etc., provides support to perform ergonomic analysis for the people relating to a different origin (like American but not Indian). Hence, the anthropometric data relating to Indian origin is to be fed into the software and then the analysis is carried out. The project consists of three phases of work.

The first phase involves visiting mono block pump industries and getting to know the assembly process and conduct work study. The second phase of this project aims at designing the existing workplace for the assembly of mono block pump using CATIA software. The third and final phase involves ergonomic analysis of the existing workplace and to provide suggestions for improvement in working conditions of the assembly of mono block pump.

\section{STAGES IN MONO BLOCK PUMP ASSEMBLY}

The various stages involved in the assembly of mono block pump components, represented by the fishbone diagram is given below.
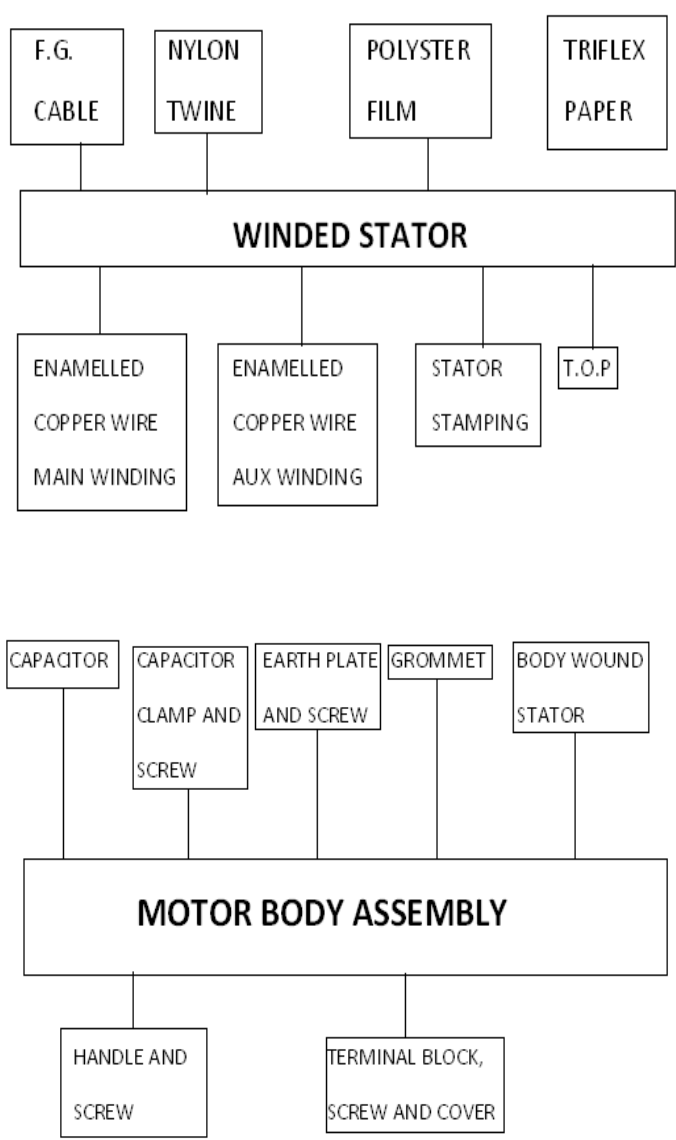


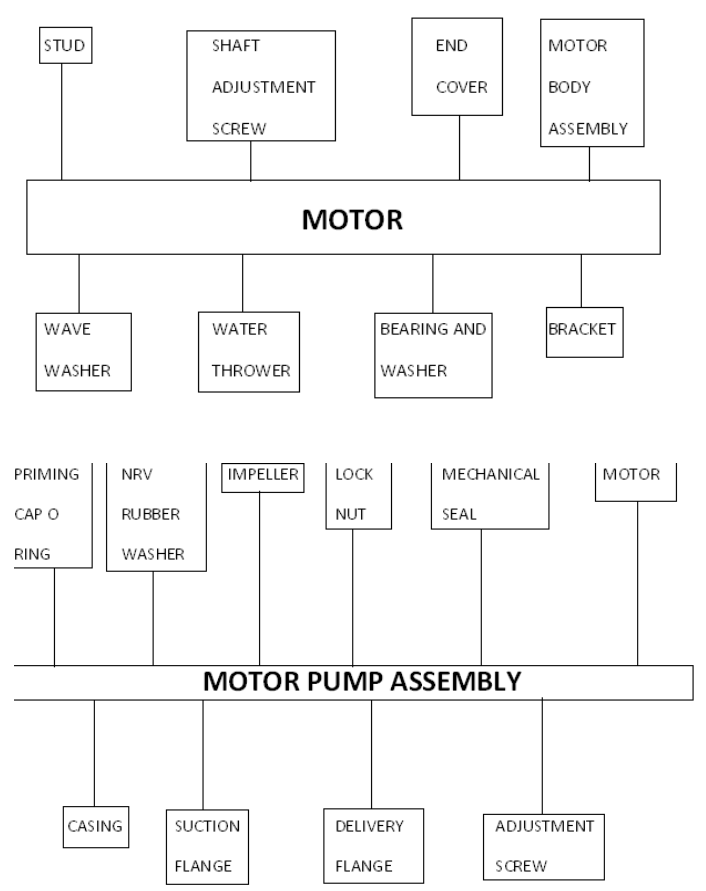

Fig-3: Stages in assembly of Mono block pump

\section{DISCOMFORT SURVEY}

A number of pump manufacturing industries have been visited in order to get a clear view regarding the assembly of mono block pump. The age group of the employees was in the range of 26 to 37 years, experience of 3 to 8 years with working time of 7 hours per day. The discomfort survey was conducted. The areas where the employees had pain while assembling the components included elbows, wrists, hands, neck, limbs, knee joints, shoulders, upper and lower back.

\section{ANTHROPOMETRIC MEASUREMENTS}

The following table provides the anthropometric measurements relating to workers of Indian origin that are to be used in creating the manikin using CATIA software.

Table-2: Anthropometric Measurements

\begin{tabular}{|l|l|l|}
\hline S.NO & DESCRIPTION & $\begin{array}{l}\text { VALUE } \\
(\mathrm{cms})\end{array}$ \\
\hline 1 & Elbow height & 107.5 \\
\hline 2 & Knuckle height & 78.4 \\
\hline 3 & Shoulder height & 145.8 \\
\hline 4 & Stature & 165.6 \\
\hline 5 & $\begin{array}{l}\text { Functional forward } \\
\text { reach }\end{array}$ & 82.5 \\
\hline 6 & Thigh clearance & 45.2 \\
\hline
\end{tabular}

\begin{tabular}{|l|l|l|}
\hline 7 & $\begin{array}{l}\text { Sitting elbow } \\
\text { height }\end{array}$ & 35.3 \\
\hline 8 & Sitting eye height & 79.6 \\
\hline 9 & Sitting height & 91.2 \\
\hline 10 & $\begin{array}{l}\text { Elbow to elbow } \\
\text { breadth }\end{array}$ & 40.7 \\
\hline
\end{tabular}

\section{RULA ANALYSIS}

The Rapid Upper Limb Assessment (RULA) analysis is used for analyzing the manikin's posture based on variables such as weight, frequency, distance, etc. It analyzes many facets of manikin posture based on the user data.

The RULA analysis examines the risk factors and all these factors are combined to give a total score that ranges from 1 to 7. The data displayed is combined with a colour indicator zone. The colour of this zone changes from green to red according to the total score. The score report consists of basic mode and advanced mode.

In the basic mode, the scores 1 and 2 (Green color) indicates that the posture is acceptable if it is not maintained or repeated for long periods of time. The scores 3 and 4 (Yellow color) indicates that further investigation is needed and changes may be required. The scores 5 and 6 (Orange color) indicates that investigation and changes are required soon. The score 7 (Red color) indicates that investigation and changes are required immediately. The score indication of advanced mode for different body parts is given below.

Table-3: The score indication of advanced mode

\begin{tabular}{|c|c|c|c|c|c|c|c|}
\hline \multirow{2}{*}{ Segment } & \multirow{2}{*}{$\begin{array}{l}\text { Score } \\
\text { Range }\end{array}$} & \multicolumn{6}{|c|}{ Color associated to the score } \\
\hline & & 1 & 2 & 3 & 4 & 5 & 6 \\
\hline Upper arm & 1 to 6 & & & & & & \\
\hline Forearm & 1 to 3 & & & & & & \\
\hline Wrist & 1 to 4 & & & & & & \\
\hline Wrist twist & 1 to 2 & & & & & & \\
\hline Neck & 1 to 6 & & & & & & \\
\hline Trunk & 1 to 6 & & & & & & \\
\hline
\end{tabular}

\subsection{Ergonomic Analysis of Existing Workplace}

The assembly process involving some of the complicated postures of the worker was identified and designed using CATIA software for ergonomic analysis. The manikin was created using the anthropometric measurements that have been taken.

\subsection{Existing Workplace}

The given figure shows the existing workplace with the worker, the assembly table and the packing area. 


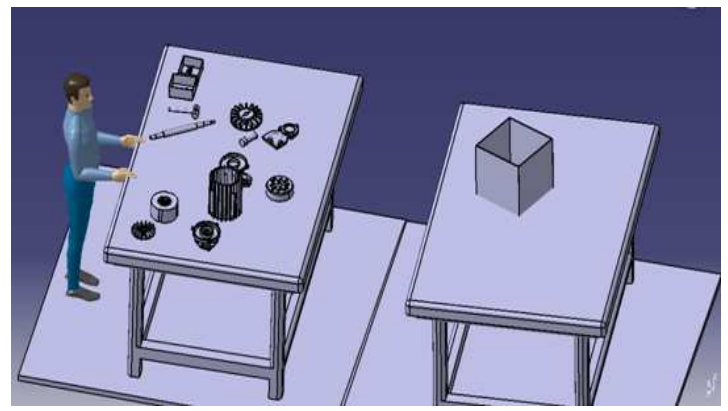

Fig-4: Existing workplace

\subsection{Reach Envelope}

A reach envelope is defined as a region that indicates all of the possible positions that the manikin can reach using only the arm and forearm.

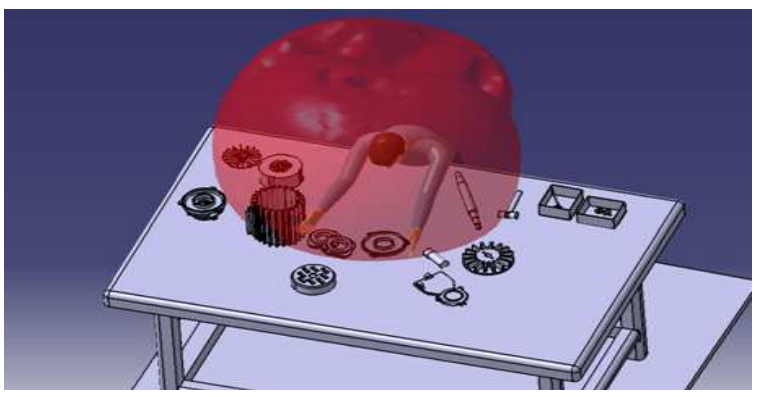

Fig-5: Reach envelope

The time for reaching the components is measured as 26.7 TMU. The eye focus and travel time is taken as 27 TMU. (1 $\mathrm{TMU}=36$ milliseconds).

The RULA analysis for different body postures while assembling the components is given below. The RULA analysis for the posture of manikin while picking up Motor body shows a final score of ' 7 ' indicating the need for immediate changes.

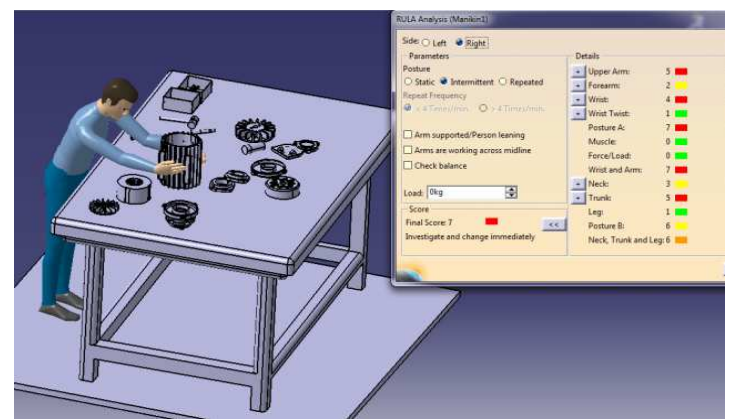

Fig-6: RULA Analysis for picking up the motor body
The time for locating, reaching, and picking and placing the motor body is measured to be 87.5 TMU.

\subsection{Fixing of Capacitor Clamp}

The figure shows the capacitor clamp being screwed into the motor body. The RULA analysis for the posture gives the score of ' 7 ' for both hands. The analysis is done in 'Repeated' mode i.e. the action is performed more than 4 times a minute.

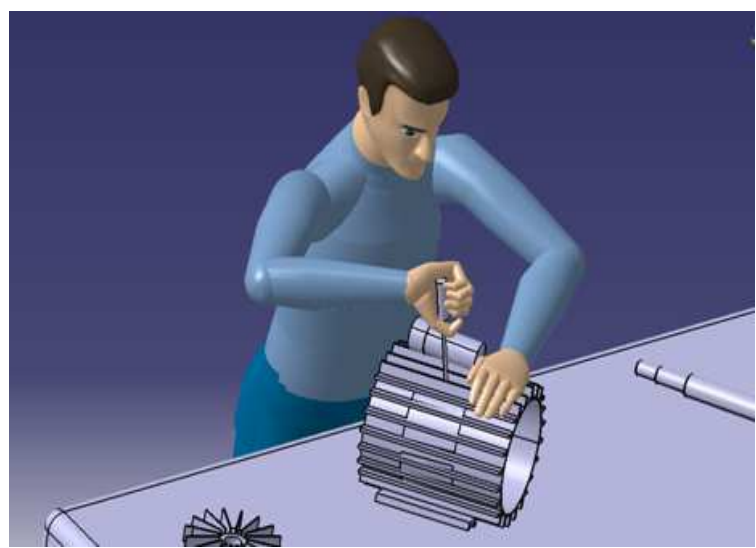

Fig-7: Fixing the capacitor clamp

The time for locating, reaching, picking, turning and applying pressure is measured to be 352.8 TMU.

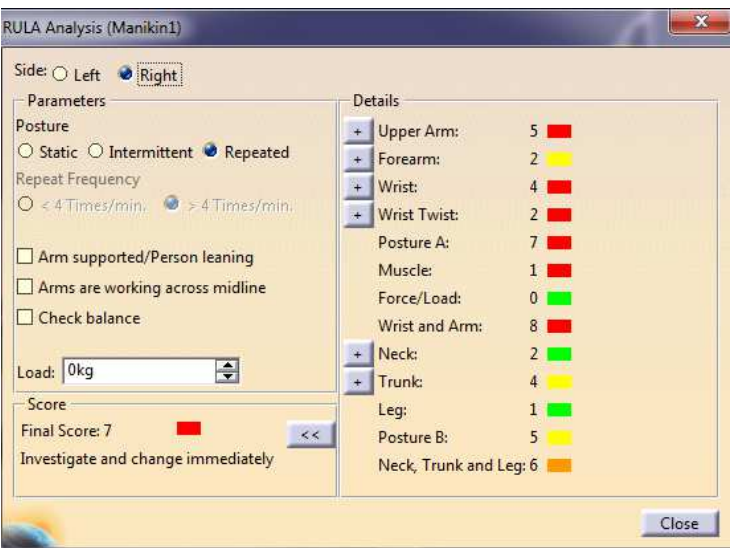

Fig-8: RULA analysis

\subsection{Moving the Assembled Component to Packing} Area

The figure shows the worker carrying the assembled pump from the assembly section to the packing area manually. The RULA analysis gives the score of ' 7 ' as the worker carries the pump which weighs around $5 \mathrm{~kg}$, intermittently the whole day. 


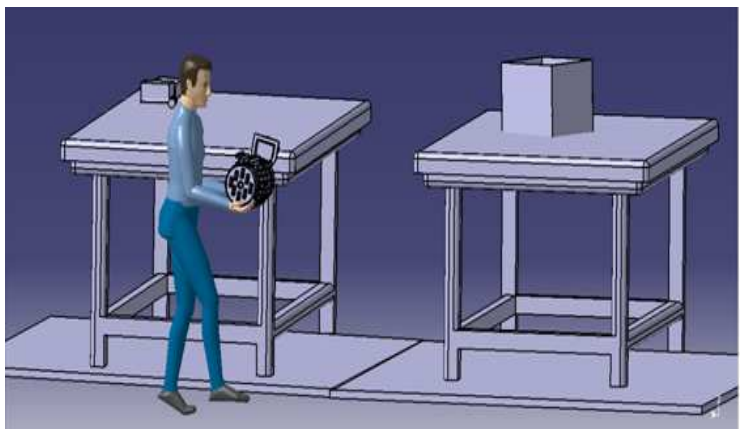

Fig-9: Moving the assembled pump to the packing section

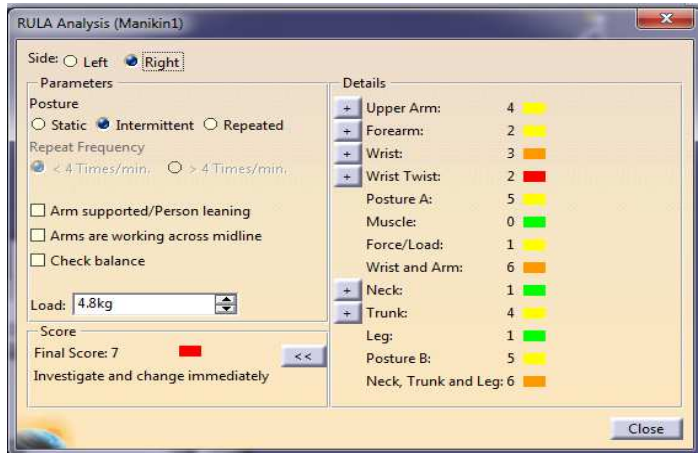

Fig-10: RULA analysis

The time for picking and moving the component is measured to be 542.2 TMU.

\section{RESULTS AND DISCUSSIONS}

As seen from the results of the RULA analysis, it is clear that some investigation and changes should be made to the existing workplace in order to save the worker from musculoskeletal disorders. The overall time for carrying out these operations is 982.5 TMU. The total time for assembly and packing is measured to be 35 minutes. Some possible modifications that can be made efficiently are as follows.

The dimension of the worktable can be changed so that it suits the worker of 5 th percentile. As the workers of 5 th percentile can work effectively in the worktable, it automatically suits the workers with 95 th percentile easily. Some identification marks are made on the worktable indicating the maximum reach envelope of the worker so that the worker can lift the components with ease as all the components lie within the functional forward reach of the worker. This will surely minimize the reaching time to around 17.5 TMU. This in turn will reduce time for all the remaining activities. A manually operated roller conveyor can be used to carry the assembled pump to the packing section. This eliminates the stress acting on both hands of the worker and the time for moving the component will also be reduced to around 187 TMU. This will reduce the overall time for carrying out these operations to around 487 TMU. This can even reduce the total assembly time to 27 minutes. The conceptual improved design with the reach envelope and with attached conveyor is shown in the figure 11 .

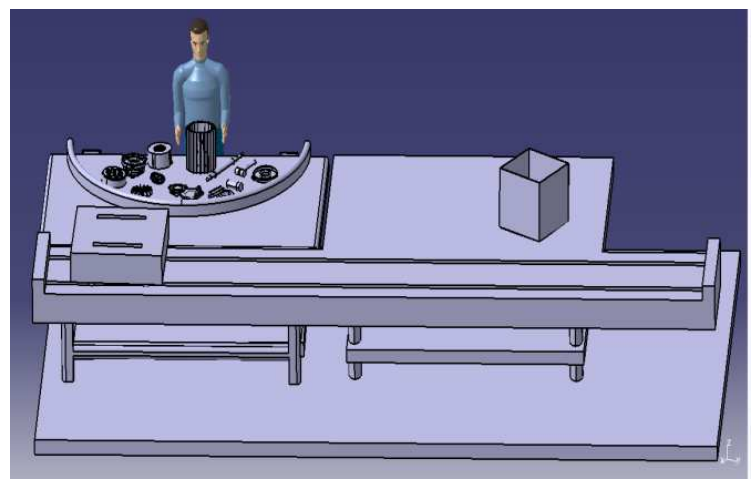

Fig-11: The conceptual improved design

\section{CONCLUSIONS}

The above improved design is one preferable case though there may be variety of solutions to the problem depending upon the economic conditions of the industry. For further improvements, the use of a hydraulic press for fixing of stator, use of screw gun to screw the capacitor clamp, use of the automatic conveyor to move the pump to the packing section can be done. Although the initial investments may be high, it would lead to better working environment for the shop floor employees thereby improving the rate of production.

\section{ACKNOWLEDGEMENTS}

We would like to thank Sharp Liqtech Industries, Coimbatore, for lending their support to carry out our research work and would like to thank A. Nandha kumar, Department of Production Engineering, PSG College of Technology, for his constant enthusiasm and support throughout the research.

\section{REFERENCES}

[1]. Jonathan M Weaver, Nader G Zamani, "CATIA V5Tutorials in Mechanism design and Animation", Schroff Development Corporation, 2007.

[2] Martin Helander, "A Guide to Human factors and Ergonomics", CRC Press Taylor \& Francis Group, Boca Raton London New York, 2006

[3] John.R.Wilson, "Fundamentals of ergonomics in theory and practice", Applied Ergonomics, Volume 31, Issue 6, December 2000.

[4] Debkumar chakraborthy, "Indian Anthropometric Dimensions for Ergonomic Design Practice", National Institute of Design, 1997. 
[5] Lisa steiner, Pauline lewis, "Implementation of ergonomics process at a U.S. surface coal mine", International journal of industrial ergonomics, volume 37, 2007.

[6] Gary A. Mirka, "Development of an ergonomics guideline for the furniture manufacturing industry", Applied Ergonomics, Volume 36, Issue 2, March 2005.

[7] Martand Telsang, "Industrial Engineering and Production Management", 2nd edition, S.Chand, 2002

[8] Richard B. Chase, "Operations and Supply Management", 12th edition, S.Chand, 2010. 